\title{
Liv \\ GERMINAÇÃO E CRESCIMENTO IN VITRO DE Dendrobium nobile LINDL. SEM SUBCULTIVO EM MEIO DE CULTURA ALTERNATIVO
}

\section{BIOENG}

\author{
J. S. Soares ${ }^{1 *}$, L. M. Ribeiro ${ }^{2}$, J. C. Sorgato ${ }^{2}$
}

${ }^{1}$ UEMS - Universidade Estadual de Mato Grosso do Sul, Pós-Graduação em Recursos Naturais - PGRN, Campus de Dourados, MS, Brasil

2 UFGD - Universidade Federal da Grande Dourados, Pós-Graduação em Produção Vegetal, Faculdade de Ciências Agrárias, Dourados, MS, Brasil

Article history: Received 24 October 2017; Received in revised form 30 November 2017; Accepted 04 December 2017; Available online 27 December 2017.

\section{RESUMO}

O cultivo in vitro de orquídeas possibilita elevadas porcentagens de germinação, quando comparadas a germinação natural dessas espécies, pois suas sementes possuem pouca ou nenhuma reserva nutritiva. Objetivou-se avaliar diferentes volumes de suspensão de sementes na propagação in vitro de Dendrobium nobile Lindl. var. nobilius e var. comet king em meio alternativo, sem subcultivos. Foram utilizadas $0,02 \mathrm{~g}$ de sementes de cada planta e desinfestadas em solução de hipoclorito de sódio a $0,8 \%$, por 15 minutos, sendo diluídas em água estéril até completar $60 \mathrm{~mL}$. Em ambiente asséptico, procedeu-se a semeadura in vitro. Foram pipetados 2, 3 ou $4 \mathrm{~mL}$ de cada suspensão de sementes em frascos de vidro de $600 \mathrm{~mL}$ providos de tampa metálica e contendo $80 \mathrm{~mL}$ do meio de cultura alternativo. As culturas foram transferidas para sala de crescimento com temperatura e fotoperíodo controlados $(25 \pm$ $2{ }^{\circ} \mathrm{C}$; 16 horas) permanecendo por seis meses nessas condições. O maior número de sementes potencialmente viáveis $\left(426 \mathrm{mg}^{-1}\right)$ foi observado em $D$. nobile var. nobilius, enquanto $D$. nobile var. comet king apresentou $164 \mathrm{mg}^{-1}$ sementes potencialmente viáveis. A variedade nobilius apresentou maiores resultados no número de plantas total e de plantas vivas, número de folhas, número e diâmetro de pseudobulbos e comprimento da maior raiz, característica dessa variedade, que é mais vigorosa. A inoculação de $2 \mathrm{~mL}$ foi mais eficiente para a micropropagação das duas plantas, havendo menos concorrência entre as plântulas no frasco.

Palavras-chave: Inoculação, micropropagação, Orchidaceae.

\section{SEED QUANTITY ON IN VITRO CULTIVATION OF Dendrobium nobile LINDL. IN ALTERNATIVE CULTURE MEDIA WITHOUT SUBCULTURE}

\begin{abstract}
The in vitro orchid cultivation results in high percentages of germination when compared to the natural germination of these species, because their seeds have few or any nutritional reserves. The objective of this study was to evaluate different amounts of seeds in the in vitro propagation of Dendrobium nobile Lindl. var. nobilius and var. comet king in alternative medium, without subcultures. $0.02 \mathrm{~g}$ of seeds of each plant were used and disinfested in $0.8 \%$ sodium hypochlorite solution for 15 minutes, being diluted in sterile water until $60 \mathrm{~mL}$ was reached. In the aseptic environment, in vitro seeding was carried out 2, 3 or $4 \mathrm{~mL}$ of each seed suspension were pipetted into $600 \mathrm{~mL}$ glass vials provided with a metal stopper and containing $80 \mathrm{~mL}$ of the alternative culture medium. The cultures were transferred to the growth room with controlled temperature and photoperiod $\left(25 \pm 2{ }^{\circ} \mathrm{C}, 16\right.$ hours) remaining for
\end{abstract}

"jacke.schultz@gmail.com 
six months under these conditions. The highest number of potentially viable seeds $\left(426 \mathrm{mg}^{-1}\right)$ was observed in D. nobile var. nobilius, while D. nobile var. comet king showed $164 \mathrm{mg}^{-1}$ potentially viable seeds. The nobilius variety showed higher results in the total number of plants and live plants, number of leaves, number and diameter of pseudobulbs and length of the largest root, characteristic of this variety, which is more vigorous. The inoculation of $2 \mathrm{~mL}$ was more efficient for the micropropagation of the two plants, with less competition between the seedlings in the flask.

Keywords: Inoculation, micropropagation, Orchidaceae.

\section{INTRODUÇÃO}

O cultivo comercial de espécies de orquídeas representa atividade com grande importância no agronegócio mundial de flores e plantas ornamentais, movimentando anualmente dezenas de bilhões de dólares (JUNQUEIRA \& PEETZ, 2010; ALVES et al., 2013).

O gênero Dendrobium é constituído de plantas de fácil cultivo e que florescem em grande escala (MELLO \& PANTOJA, 2014). Dentre suas espécies destaca-se o Dendrobium nobile Lindl., que é originária da China e do Himalaia, amplamente cultivada e comercializada no Brasil, destacando-se no mercado das plantas de corte e envasadas (ASSIS et al., 2010; ROSA et al., 2014; SORGATO et al., 2015a). Além do aspecto ornamental e valor comercial na floricultura, esta orquídea é muito utilizada na tradicional medicina chinesa por suas propriedades antioxidante, anti-inflamatória, imunomoduladora, anti-tumoral e antimutagênica (LORENZI, 2013; LAM et al., 2015).

Diferente da maioria das famílias botânicas, as sementes de Orchidadecae não possuem reservas nutritivas suficientes para promover a germinação. Desta forma, na natureza, as sementes germinam em simbiose com fungos micorrízicos. Nesse sentido, a produção de orquídeas in vitro é

\section{MATERIAL E MÉTODOS}

O experimento foi realizado no Laboratório de Cultivo in vitro da Faculdade de Ciências Agrárias (FCA) da Universidade Federal da Grande Dourados (UFGD). importante, pois possibilita um grande número de mudas em pequeno espaço físico, pouco tempo de cultivo e com elevada qualidade sanitária (FARIA et al., 2012; ABRÃO et al., 2014).

Entre os fatores que interferem na eficiência da micropropagação estão a composição dos meios nutritivos, os reguladores de crescimento, a condição de luminosidade, os tratamentos prégerminativos, o número de subcultivos e o número de indivíduos por frasco de cultivo (SOARES et al., 2008; KUHN et al., 2014; SILVA et al., 2015).

No processo de semeadura in vitro, o volume da suspensão de sementes inoculado associado à sua viabilidade pode influenciar o sucesso desse procedimento, uma vez que, a superpopulação de indivíduos no frasco de cultivo, quando não realizado o subcultivo, pode ocasionar o esgotamento das reservas nutritivas dos meios de cultura ocasionando o lento desenvolvimento ou a morte das estruturas vegetais formadas.

Dessa forma, objetivou-se com este trabalho avaliar o efeito de diferentes volumes de inoculação de sementes no cultivo in vitro de Dendrobium nobile var. nobilius e de Dendrobium nobile var. comet king, sem subcultivos, em meio de cultura alternativo.

Foram utilizadas sementes de Dendrobium nobile Lindl. var. nobilius e var. comet king provenientes de cápsulas produzidas mediante autopolinização manual e colhidas 12 meses após a 
identificação visual da formação do fruto. Após a assepsia com álcool etílico $70 \%$, as cápsulas foram abertas e, 0,005 $\mathrm{g}$ de sementes submetidas ao teste de tetrazólio para determinação da viabilidade. Foram identificadas 164 sementes viáveis $\mathrm{mg}^{-1}$ para a variedade comet king e 426 sementes viáveis $\mathrm{mg}^{-1}$ para a variedade nobilius. Após a confirmação da viabilidade procedeu-se a semeadura in vitro.

Foi utilizado meio de cultura proposto por Campos (2002), modificado por adição de $70 \mathrm{~g}$ de tomate tipo italiano sem sementes e casca, $50 \mathrm{~g}$ de banana nanica sem casca, $3 \mathrm{~mL}$ de fertilizante NPK 10-10-10, 7 g de ágar bacteriológico, $25 \mathrm{~g}$ de sacarose $\left(\mathrm{C}_{12} \mathrm{H}_{22} \mathrm{O}_{11}\right), 150 \mathrm{~mL}$ de água de coco, $3 \mathrm{~g}$ de carvão ativado e água destilada até completar um litro.

$\mathrm{O} \mathrm{pH}$ foi ajustado para 5,8 $(\mathrm{KOH} 1,0$ M) após homogeneização do meio no liquidificador. Posteriormente $80 \mathrm{~mL}$ do meio de cultura foram transferidos para frascos de $600 \mathrm{~mL}$ providos de tampa metálica, sendo, a seguir, esterilizados em autoclave por 20 minutos a $120{ }^{\circ} \mathrm{C}$ e uma atmosfera de pressão. Na sequência, os frascos foram transferidos para ambiente asséptico para realização da semeadura in vitro.

Para a semeadura in vitro, foram pesadas separadamente $0,01 \mathrm{~g}$ de sementes de cada variedade estudada. As sementes foram desinfestadas por 15 minutos em solução a $0,8 \%$ de hipoclorito de sódio comercial (CAMPOS, 2002). Decorrido este tempo a suspensão foi diluída para 50 $\mathrm{mL}$ com água destilada estéril e, em ambiente asséptico, procedeu-se a semeadura utilizando pipetador automático.

\section{RESULTADOS E DISCUSSÃO}

Houve efeito significativo da interação entre as variedades e o volume de inoculação sobre a maioria das variáveis estudadas. O resumo das análises de variância e a média geral das variáveis, bem como a significância ou não dos
Em cada frasco de cultivo inoculouse 2, 3 ou $4 \mathrm{~mL}$ de uma das suspensões de sementes, com quatro repetições constituídas de três frascos cada. Os volumes de inoculação (2, 3 ou $4 \mathrm{~mL}$ ) corresponderam, na variedade nobilius, a 170, 256 e 341 sementes por frasco de cultivo e, na variedade comet king a 66, 98 e 131 sementes, respectivamente.

Após a semeadura, os frascos, devidamente tampados, foram alocados em sala de crescimento com temperatura e fotoperíodo controlados $\left(25 \pm 2{ }^{\circ} \mathrm{C}, 16 \mathrm{~h}\right.$, $20 \mu \mathrm{mol} \mathrm{m}^{-2} \mathrm{~s}^{-1}$ ).

Seis meses após a semeadura, as plântulas foram retiradas dos frascos $\mathrm{e}$ avaliadas quanto ao número de plântulas vivas (PV) e mortas (PM), calculando-se a porcentagem de germinação $(\% \mathrm{G})$ e de sobrevivência (\%SOB), por meio das expressões:

$$
\begin{aligned}
& \% G=\left[(P V+P M) / N^{\circ}\right. \text { sementes } \\
& \text { inoculadas }] \times 100 \\
& \% S O B=[P V /(P V+P M)] \times 100 \\
& \text { Após a completa remoção do }
\end{aligned}
$$
substrato, as plântulas vivas foram avaliadas quanto ao número de pseudobulbos e de folhas, diâmetro dos pseudobulbos e comprimento da maior raiz.

Como delineamento experimental, foi utilizado DIC com tratamentos arranjados em esquema fatorial $2 \times 3$ (duas variedades de $D$. nobile e três volumes de inoculação) com 4 repetições. Após a ANOVA, as médias foram submetidas à análise de regressão até o nível de $5 \%$ de probabilidade, com auxílio do programa SISVAR (Programa de Análises Estatísticas v.5.3. Universidade Federal de Lavras, MG).

fatores analisados são apresentados na Tabela 1. 
Tabela 1. Resumo das análises de variância da porcentagem de germinação $(\% \mathrm{G})$ e da sobrevivência (\%SOB), do número de plântulas (NP), de folhas (NF), de pseudobulbos (NB), diâmetro dos pseudobulbos (DB) e comprimento da maior raiz (CR) de Dendrobium nobile var. nobilius e var. comet king. UFGD, Dourados-MS, 2017.

\begin{tabular}{lcccccccc}
\hline & \multicolumn{8}{c}{ Quadrados médios } \\
\hline F.V. & GL & $\% \mathrm{G}$ & $\% \mathrm{SOB}$ & $\mathrm{NP}$ & $\mathrm{NF}$ & $\mathrm{NB}$ & $\mathrm{DB}$ & $\mathrm{CR}$ \\
Variedade & 1 & $1,54^{*}$ & $201,15^{* *}$ & $131,93^{* *}$ & $2,45^{* *}$ & $95,40^{* *}$ & $11,60^{* *}$ & $153,85^{* *}$ \\
Volume & 2 & $0,03^{\mathrm{ns}}$ & $56,13^{* *}$ & $27,24^{* *}$ & $1,19^{* *}$ & $29,59^{* *}$ & $1,80^{* *}$ & $18,38^{* *}$ \\
Var. x Vol. & 2 & $0,078^{\mathrm{ns}}$ & $46,83^{* *}$ & $2,36^{*}$ & $0,39^{* *}$ & $36,80^{* *}$ & $1,19^{* *}$ & $4,50^{* *}$ \\
Resíduo & 18 & 0,29 & 0,28 & 0,65 & 0,02 & 0,60 & 0,01 & 0,17 \\
C.V.(\%) & & 6,0 & 7,7 & 7,1 & 8,9 & 5,42 & 1,23 & 9,2 \\
Média & & $79,6 \%$ & $62,6 \%$ & 136,3 & 2,0 & 1,1 & $2,6 \mathrm{~mm}$ & $28,0 \mathrm{~mm}$ \\
\hline
\end{tabular}

** significativo, a $1 \%$ de probabilidade, pelo teste $\mathrm{F}$

* significativo, a 5\% de probabilidade, pelo teste $\mathrm{F}$

${ }^{\text {ns }}$ não significativo

A porcentagem de germinação $(\% \mathrm{G})$ de ambas as variedades foi superior a $70 \%$ em todos os volumes de inoculação testados, com \%G média de 79,6 (Tabela 1). De maneira geral, no cultivo in vitro de Dendrobium nobile, porcentagens de germinação em torno de $75 \%$ são consideradas comercialmente satisfatórias (SORGATO et al., 2015a), já que em ambiente natural essa porcentagem é baixa, em torno de 2 a $3 \%$ (CORRIE \& TANDON, 1993).

Ao analisar a Figura 1A, observa-se que, para a var. comet king, a menor $\% \mathrm{G}$ calculada $(77,7 \%)$ ocorreu quando o volume de suspensão de sementes inoculado foi de 3,06 mL. Quanto à porcentagem de sobrevivência (\%SOB), o menor valor calculado $(\% \mathrm{SOB}=0 \%)$ foi encontrado com a inoculação de 3,67 mL e o maior $(\% \mathrm{SOB}=100 \%)$ quando se utilizou $1,54 \mathrm{~mL}$ de suspensão de sementes. A \%SOB da variedade comet king foi de $94 \%$ quando utilizado o volume de $2 \mathrm{~mL}$, entretanto, para os volumes de inoculação 3 e $4 \mathrm{~mL}$, não houve sobrevivência das plantas ao final do período experimental, o que permite inferir que a superpopulação de plantas induziu maior competição pelos nutrientes, esgotando o meio e ocasionando a morte dos indivíduos. Comet king sobrevive sem subcultivos por seis meses quando o número de plantas por frasco de cultivo for inferior ou igual a 60 plântulas (Figura 1B).

$\mathrm{Na}$ figura $2 \mathrm{~A}$, a maior $\% \mathrm{G}$ calculada da var. nobilius $(\% \mathrm{G}=82,58 \%)$ foi encontrada no volume inoculado de 2,92 mL. A menor \%SOB calculada $(\% \mathrm{SOB}=$ $0 \%$ ) ocorreu com o volume de $15,75 \mathrm{~mL}$ e a maior $(\% \mathrm{SOB}=100 \%)$ quando utilizado $2,14 \mathrm{~mL}$.

Após 6 meses de cultivo in vitro, a $\%$ SOB dessa variedade foi superior a $80 \%$ em todos os volumes de suspensão de sementes utilizados. 

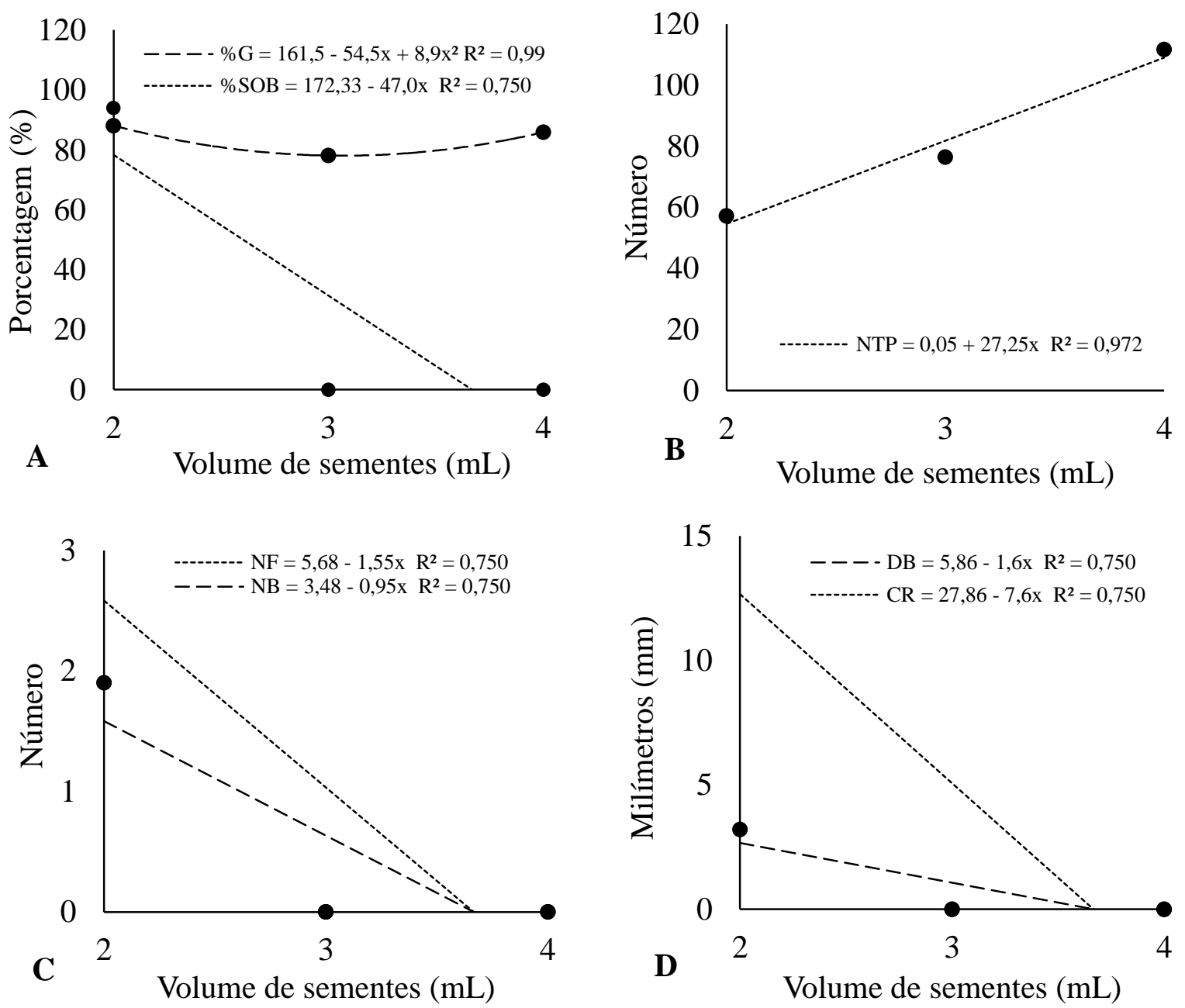

Figura 1. Valores das porcentagens de germinação $(\% \mathrm{G})$ e de sobrevivência $(\% \mathrm{SOB})(\mathbf{A})$, número total de plântulas (NTP) (B), de número de folhas (NF) e de pseudobulbos (NB) (C), diâmetro dos pseudobulbos (DB) e comprimento da maior raiz (CR) (D) de Dendrobium nobile var. comet king. UFGD, Dourados-MS, 2017. 

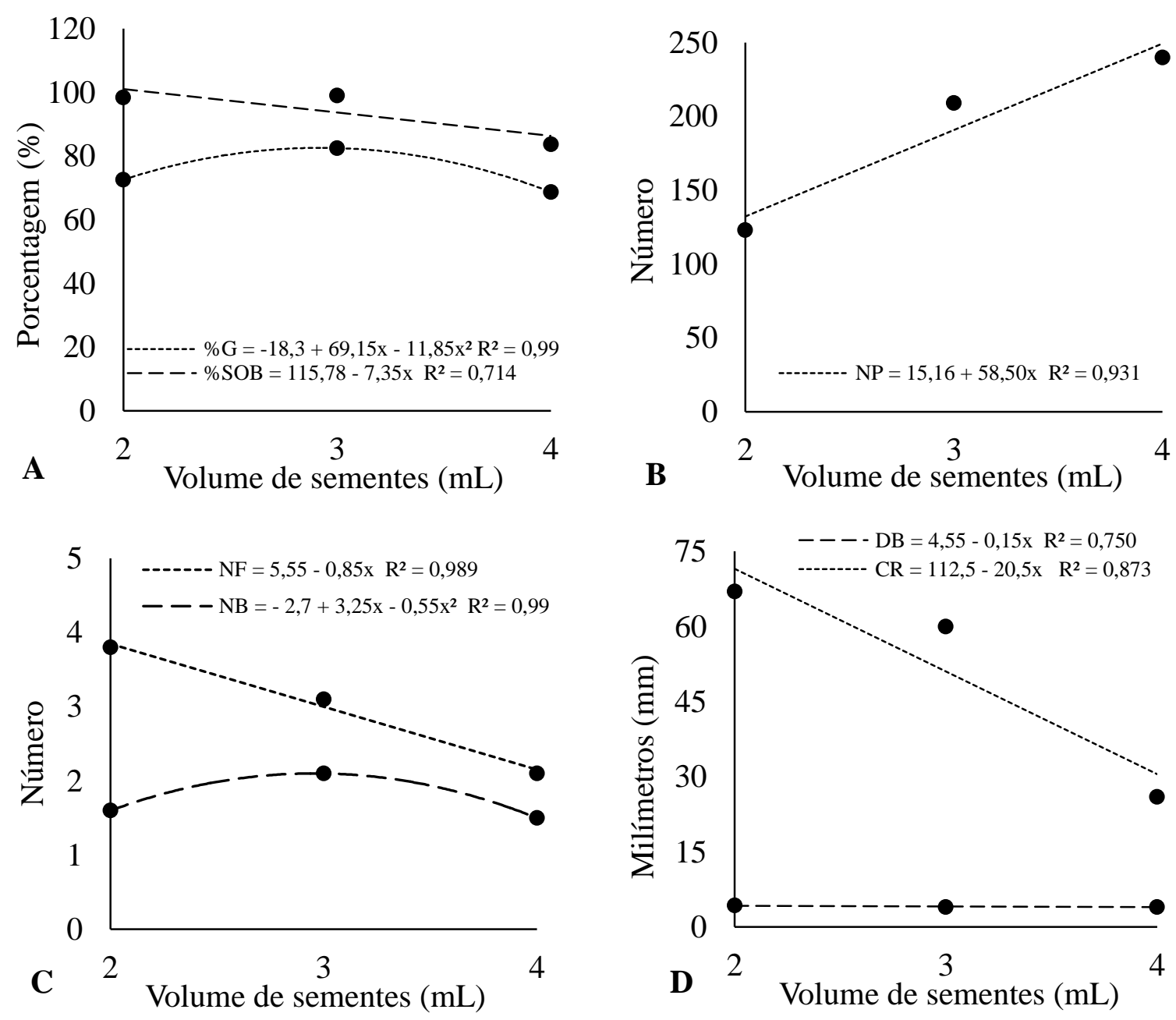

Figura 2. Valores das porcentagens de germinação $(\% \mathrm{G})$ e de sobrevivência $(\% \mathrm{SOB})(\mathbf{A})$, número total de plântulas (NTP) (B), de número de folhas (NF) e de pseudobulbos (NB) (C), diâmetro dos pseudobulbos (DB) e comprimento da maior raiz (CR) (D) de Dendrobium nobile var. nobilius. UFGD, Dourados-MS, 2017.

A utilização de $2 \mathrm{~mL}$ da suspensão de sementes produziu menor número de plântulas $(123,5)$ da variedade nobilius, entretanto, com maior número de folhas $(3,8)$ e maior sistema radicular $(67,0 \mathrm{~mm})$ (Figuras 2B, 2C e 2D). A redução da competição por luz, nutrientes e espaço, culminando no aumento do crescimento de plantas foi relatada por Jorge et al. (2015), os quais verificaram que uma menor quantidade de sementes germinadas, acarretando em menos plantas por frasco, aumentou o crescimento destas.

As variáveis citadas são essenciais à fase de aclimatização ex vitro, pois as plantas passarão da condição heterotrófica para autotrófica (ASSIS et al., 2010). Nessa nova condição, a presença das folhas é fundamental para a fotossíntese e fotorrespiração o que, juntamente com pseudobulbos mais desenvolvidos ( $\mathrm{DB}=$ 4,3 mm), que são órgãos de reserva nutricional e de água, pode fazer a diferença entre a sobrevivência ou não das plantas.

Em relação ao sistema radicular das plantas estudadas, os maiores comprimentos de raiz foram observados para as duas variedades com a utilização de $2 \mathrm{~mL}(67,0 \mathrm{~mm}$ para nobilius e $15,2 \mathrm{~mm}$ para comet king) (Figuras 1D e 2D). Plântulas com sistema radicular mais desenvolvido são mais capazes de sobreviver à fase de aclimatização ex vitro, pois o sistema radicular das orquidáceas, além da função de nutrição tem também a 
finalidade de fixar as plantas no substrato (SORGATO et al., 2015b). Os resultados observados nesse trabalho, em relação ao comprimento das raízes, permitem inferir que a variedade nobilius poderá ter maior facilidade de aclimatização ex vitro do que a comet king.

Os resultados observados neste trabalho demonstram que um menor número de plantas por frasco de cultivo contribuiu tanto para o aumento da parte aérea das plantas quanto para o aumento do sistema radicular destas. Já Soares et al. (2008), estudando as orquídeas Cattleya persivaliana e $C$. loddigesii, relataram que a utilização de menos explantes (3) por

\section{CONCLUSÃO}

Quando não realizados subcultivos, o volume de $2 \mathrm{~mL}$ de suspensão de sementes é o mais indicado para a semeadura in vitro

\section{REFERÊNCIAS BIBLIOGRÁFICAS}

ABRÃO, M. C. R.; JORGE, J.; PESCADOR, R.; DE MELO FERREIRA, W.; SUZUKI, R. M. Germinação de sementes e desenvolvimento in vitro de plântulas de Cattleya loddigesii Lindl.(Orchidaceae). Revista Brasileira de Biociências, v. 12 (3):141-147, 2014.

ALVES, A. P.; SAPATINI, J. R.; SOUZALEAL, T.; FERNANDES, F. S.; MORAES, C. P. Influência da poda radical e recipientes na aclimatização ex vitro de Cattleya loddigesii Lindl. (Orchidaceae). Revista Brasileira de Biociências, v. 11 (4): 414-418, 2013.

ASSIS, A. M.; CARVALHO, J. F. R. P.; FARIA, R. T. Cultivo de orquídeas. Londrina: Mecenas, 2010. 208p.

CAMPOS D, M. Orquídeas: manual prático de cultura.Rio de Janeiro: Expressão e Cultura, 2002. 143p.

CORRIE, S.; TANDON, P. Propagation of Cymbidium giganteum Wall. Through high frequency conversion of encapsulated frasco propiciou maior crescimento da parte aérea, enquanto que a utilização de um maior número (12 explantes) propiciou o crescimento do sistema radicular.

Os resultados relativos ao crescimento das plântulas demonstram que, mesmo a utilização de $2 \mathrm{~mL}$ de suspensão de sementes, que corresponderam à 0,0004 $\mathrm{g}$ de sementes das variedades estudadas, produziu número elevado de plântulas por frasco, o que pode ter comprometido o crescimento in vitro, já que não foram realizados subcultivos, que tem o objetivo de minimizar os efeitos da competição que se estabelece dentro do frasco de cultivo (STANCATO et al., 2001).

das variedades nobilius e comet king da espécie Dendrobium nobile Lindl.

protocorms under in vitro and in vivo conditions. Indian Journal of Experimental Biology, v. 31(1): 61-64, 1993.

FARIA, R. T.; ASSIS, A. M.; UNEMOTO, L. K.; CARVALHO, J. F. R. P.Produção de orquídeas em laboratório. Londrina: Mecenas, 2012. $124 \mathrm{p}$.

JORGE, J.; JURAS, M. C. R.; SUZUKI, R. M. Germinação e crescimento inicial in vitro de Cattleya warneri T. Moore (Orchidaceae). Revista Brasileira de Biociências, v. 13(3): 134-141, 2015.

JUNQUEIRA, A. H.; PEETZ, M. S. Análise conjuntural do comércio exterior da floricultura brasileira. Revista Brasileira de Horticultura Ornamental, v. 16(1): 79-81, 2010.

KUHN, B. C.; CLAUDINO, L. O.; KUHN, S. B.; GUTIERRE, M. A. M.; MANGOLIN, C. A.; MACHADO, M. F. P. S. Micropropagação de Cattleya forbesii Lindley (Orchidaceae) usando 
combinações de auxina e citocinina. Revista Pleiade, v. 14(8): 73-82, 2014.

LAM, Y.; NG, T. B.; YAO, R. M.; SHI, J.; XU, K.; SZE, S. C. W.; ZHANG, K. Y. Evaluation of chemical constituents and important mechanism of pharmacological biology in Dendrobium plants. EvidenceBased Complementary and Alternative Medicine, v. 2015(1): 01-25, 2015.

LORENZI, H.Plantas para jardim no Brasil: Herbáceas, arbustivas e trepadeiras.Nova Odessa: Instituto Plantarum, 2013. 1120p.

MELlO, A. C. F.; PANTOJA, S. C. S. Orquídeas no paisagismo da área urbana de Ipanema-RJ. Revista Eletrônica Novo Enfoque, v. 18 (18): 87-108, 2014.

ROSA, Y. B. C. J.; RAMOS, F. Z.; SOUZA, R. G.; SOARES, J. S.; ROSA JUNIOR, E. J.; HOFFMANN, N. T. K.; ROSA, D. B. C. J.; SORGATO, J. C. Influência da luminosidade no crescimento e floração de Dendrobium nobile Lindl. Revista Brasileira de Horticultura Ornamental, v. 20 (1): 79-86, 2014.

SILVA, J. A. T.; TSAVKELOVA, E. A.; NG, T. B.; PARTHIBHAN, S.; DOBRÁNSZKI， J.; CARDOSO, J. C.;
RAO, M. V.; ZENG, S. Asymbiotic in vitro seed propagation of Dendrobium. Plant cell reports, v. 34(10): 1685-1706, 2015.

SOARES, J. D. R., RODRIGUES, F. A., DE ARAUJO, A. G., PASQUAL, M., DE ASSIS, F. A. Crescimento in vitro de orquídeas: quantidade de meio e número de explantes. Ceres, v. 55(1): 49-53, 2008.

SORGATO, J.C.; ROSA, Y. B. C. J.; SOARES, J. S.; LEMES, C. S. R.; SOUSA, G. G. D. Light in intermediate acclimatization of in vitro germinated seedlings of Dendrobium phalaenopsis Deang Suree. Ciência Rural, v. 45(2): 231-237, 2015b.

SORGATO, J. C.; SOARES, J. S.; PINTO, J. V. C.; ROSA, Y. B. C. J. Potencial germinativo de sementes e qualidade de keikis de Dendrobium nobile em diferentes fases do desenvolvimento dos frutos. Ciência Rural, v. 45(11): 1965-1971, 2015a.

STANCATO, G. C.; BEMELMANS, P. F.; VEGRO, C. L. R. Produção de mudas de orquídeas a partir de sementes in vitro e sua viabilidade econômica: estudo de caso. Revista Brasileira de Horticultura Ornamental, v.17(1): 25-33, 2001. 